\title{
The use of online debates in teaching pharmacotherapy
}

\author{
Theresa L. Charrois and Shelley Appleton \\ School of Pharmacy, Curtin University, Australia
}

\section{KEYWORDS}

Debates, critical thinking, argumentation skills, pharmacotherapy

\begin{abstract}
Given changes in the final year pharmacotherapy unit structure and calendar, along with a need to introduce assessments to encourage critical thinking, it was decided that online debates of therapeutic controversies would be beneficial. The primary objective was to assess the impact of teaching strategies on the development of argumentation skills and informal reasoning in pharmacy students. Students were provided with an introduction to argumentation followed by two formal debates, with feedback provided in between. Four debate groups were randomly selected for evaluation. In debate one, all groups posted one argument and all arguments were rationalistic and ranked as Level 3. For debate two, a total of 33 arguments were evaluated, with an overall median ranking of Level 2. Again, all debates were categorised as rationalistic. In general, students felt there was too much workload associated with the assignment. Changes in the future include providing the debates in patient scenarios to increase practical applicability.
\end{abstract}

\section{Background}

\section{Context:}

Pharmacotherapy teaching at Curtin University has traditionally involved the lecture and tutorial format common to most units. Lectures, presented in a didactic format, are given on a variety of topics ranging from nutrition to oncology, by experts in the field. The tutorials are meant to consolidate learning from the lectures by putting them in the context of patient cases. Little change from this model of teaching pharmacotherapy has been made over the last number of years. The adoption of a blended learning environment was necessary in light of administrative and logistical changes to the fourth year pharmacy calendar. In Semester 1, 2011, fourth year students were only going to be on campus for six weeks of term. This was preceded by six weeks of clinical placements. The constriction of face-to-face time led to reconsidering how the Pharmacotherapy unit could be better delivered. It was decided, in conjunction with the fourth year coordinator and other pharmacotherapy lecturers, to implement an online component in order to reduce the number of face-to-face tutorials in the six weeks of time spent on campus. 
In addition to this, it was felt that the introduction of an assessment that focused on critical thinking skills would be beneficial. Pharmacy students require the development and growth of a multitude of skills during their four years of training. These include communication skills, evaluation and interpretation skills, as well as critical thinking (Australian Pharmacy Council, 2009). These skills are part of accreditation standards in various jurisdictions (Australian Pharmacy Council, 2009; Accreditation Council for Pharmacy Education, 2011), and as such require activities that foster and assess these skills.

The Australian Pharmacy Council Accreditation Standards (2009) specifically state (p. 10) the following:

- Graduates from a pharmacy program should be able to have the following generic attributes:

○ Communication: the ability to communicate information, arguments and analyses effectively

o Critical thinking: the ability to analyse issues logically, consider different options and viewpoints, and make informed decisions.

\section{Rationale:}

Clinical decision making and problem solving with regard to patient care are difficult skills for pharmacy students to master, as they involve critical thinking skills. The problem with the majority of teaching and learning in pharmacy education is that it promotes rote learning (Taylor, 2007). Students often cite this as a preference in terms of learning strategy as it has either previously brought them success, or requires less mental fortitude than a strategy that would incorporate deeper learning (Novak, 2003).

Debate and argumentation have been proposed and evaluated as a method to develop these skills (Erstad, 1994; Lieberman et al 2000; Saito \& Fujinami, 2011). Informal reasoning, which is the thought process that is involved in working out contentious problems with no clear answers, is also part of the argumentation process. Bloom's taxonomy identifies critical thinking and reasoned argument as high level thinking associated with evaluating skills (Krathwohl, 2002).

Debates allow students to not just identify that there is a problem or issue to resolve, but also a deeper analysis of the issue at hand. This includes identification of evidence, appraisal and critique of evidence and reasoning of the issue for a potential solution.

These skills are also necessary as health care professionals are inundated with new evidence all the time; and appraisal and critique of evidence is the only way to separate the valid from the invalid.

Debates have been used in tertiary education of health care professionals. For example, in a graduate level periodontics course, introduction of a debate assignment was evaluated 
(Saito, 2010). The assignment focused on information collection, analysis and evidencebased discussions. The debates were judged by faculty using undefined, invalidated criteria. The students also participated in a pre and post-test which showed no difference in their understanding of concepts (Saito, 2010).

In an earlier study, debates in a medical unit were evaluated using focus groups and surveys (Liebermann, 2000). The students perceived the debates as exercises in critical thinking not content acquisition, and the debates promoted research-analysis skills. The most common complaints from the students were related to both workload and time (Liebermann, 2000).

In terms of the pharmacy setting there are a few examples in the literature describing the use of debates in curricula. A pharmacy course focusing on the United States of America (USA) health care system included debates in their course, however the study did not analyse any of the debates or investigate critical thinking, reasoning, or level of argumentation by the students (Poirier, 1997). The majority of students (80\%) felt the learning activity should be repeated again and the major complaint associated with the debates was that the students had to work as groups. This was similar to another study that looked at the introduction of online debates to discuss issues of controversy in the health care system of the USA ( $\operatorname{Lin}, 2007)$. In this study, the researchers evaluated the assessments by using thematic analysis of qualitative data collected from the online debates and student evaluations of the course. They concluded that there was an increase in enthusiasm and depth of knowledge from the students; however, they include no explanation as to how their analysis was conducted.

Another example of debates in pharmacy curriculum was in a post-graduate course for pharmacy students. Topics included primarily regulatory issues. Again, evaluation of these debates was ad hoc by faculty, with invalidated methods being used for analysis (Sookaneknun, Suttajit, Ploylearmsang, Kanjanasilp, \& Maleewong, 2009). A pharmacokinetic course at University of Tucson included a debate component as an assignment (Erstad, 1994). Again, faculty evaluation of the debates was conducted in a similar manner to the aforementioned studies where no specific validated measure was used to assess the student's level of debate or critical thinking skills.

\section{Problem to be solved:}

Given the changes in the unit structure and calendar, along with a defined need to introduce assessments designed to encourage higher level, critical thinking, it was decided that online debates of therapeutic controversies would be beneficial in addressing the problem. In addition, a validated method for analysis of argumentation and informal reasoning would be employed to improve upon methods used in previous studies. 


\section{Research objectives:}

The specific research objectives were to:

1. Assess the impact of teaching strategies on the development of argumentation and informal reasoning skills in pharmacy students.

2. Assess the impact of teaching strategies on student perceptions of learning argumentation and informal reasoning skills as taught in the context of pharmacotherapy.

\section{Approach}

During orientation to the unit, students were provided with a brief introduction to argumentation and given a scenario of its potential usefulness in practice (Appendix 1). Students were also given a brief overview of requirements of the assessment.

Students were asked to split themselves into groups of 3-5 students.

Two debates were scheduled during their six weeks of term spent on campus (weeks 7-12 of semester 1, 2011). The first debate was for formative feedback only. Students were to engage in the online debate, with participation ending on a specified date, approximately two and a half weeks after the start date. Topics included pharmacotherapy related concepts from their previous pharmacotherapy units. After this time, feedback was provided to the class as a whole during lecture time. The main points of feedback related to better structure of their argument using Toulmin's (2003) argument structure (see Figure 1) as presented during orientation. After this feedback was provided, students were assigned debate two, with different topics, associated affirmative and negative positions, and different teams. The second debates were based on topics from their current pharmacotherapy unit and were graded as part of their final assessment. Each group was sequentially assigned a topic and nominated either an affirmative or negative position to argue. 


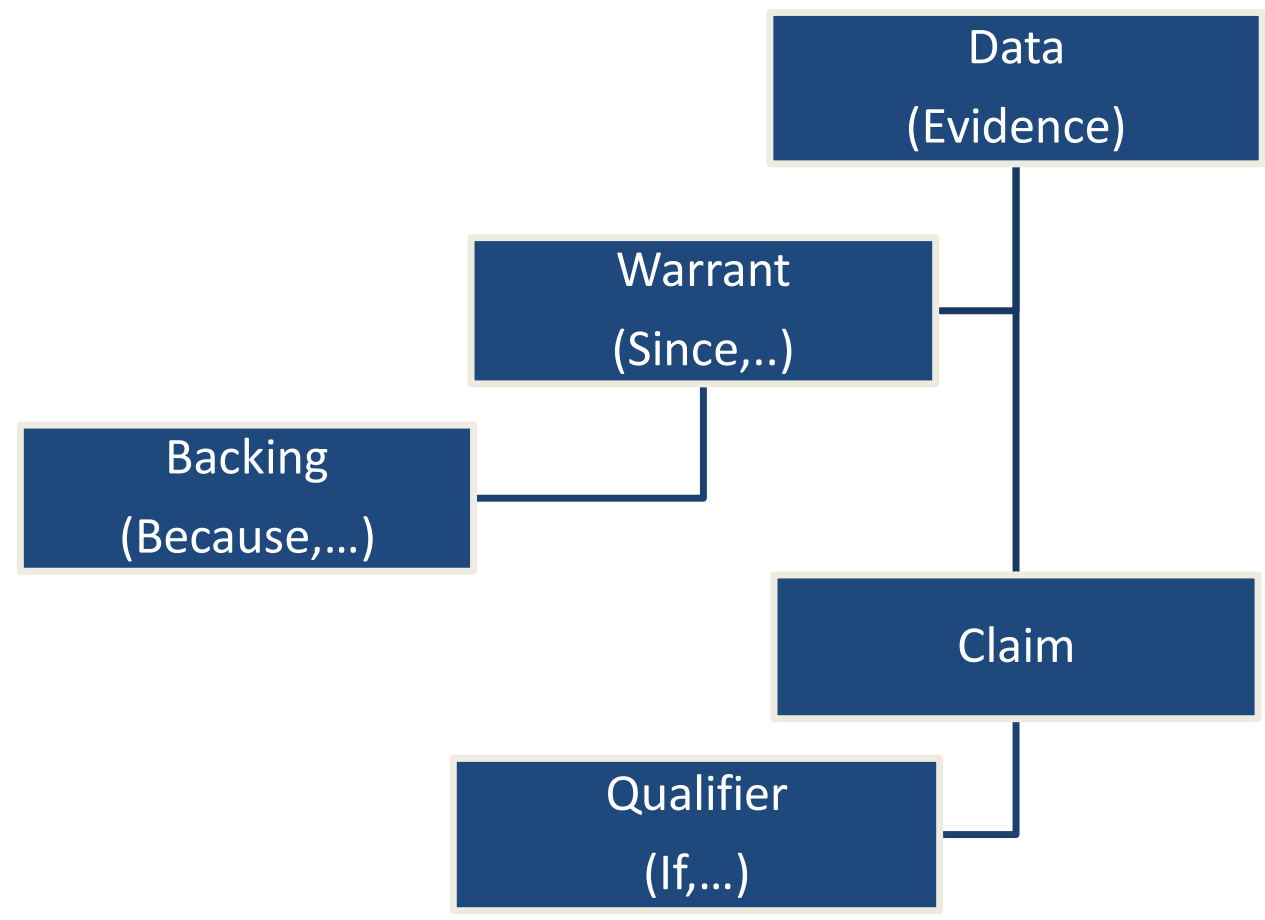

Figure 1: Toulmin's Argument Diagram (adapted from Toulmin, 2003).

Students were provided with the criteria on which the debates would be marked. Overall, $90 \%$ of the assessable marks for the activity were based on the group debate performance (see breakdown below):

Participation (online presence and engagement in the debate) $30 \%$

Evidence provided 30\% (including evidence evaluation)

Did you use evidence to strengthen your debate?

Did you critically evaluate the evidence you used?

Did you provide references for evidence you used?

Strength of argument $30 \%$

How convincing is your argument?

Did you follow a concise and consistent format to your argument structure (e.g. Toulmin's argument structure (2003))?

The remaining $10 \%$ of marks was based on an individual performance in producing a final report where students were asked to consider the following points:

- Did the debates help reinforce material learned in the lectures and tutorials?

- What challenges did the debate assignment pose to you?

- Can you see a usefulness of this skill in practice? Why or why not? 
The students were encouraged to not use the final report as an evaluation of the assessment per se, as that could be done using eVALUate, Curtin's online system for gathering and reporting student feedback on their learning experiences.

\section{Technology:}

Debates were conducted online at www.createdebate.com. The site is a public domain that allows anyone to create a login and participate in debates ranging from political to entertainment based issues. The site has a private feature that allowed the pharmacotherapy debates to only be seen by the students enrolled in the unit. A domain specific to the unit was created (http://curtinpharmacy.createdebate.com/) and students were provided with information to create a group specific login.

The site was set up with a separate webpage for each debate, with the affirmative and negative positions clearly labelled (see Figure 2). The administrator (Unit coordinator) checked the posts weekly to ensure groups were engaging in the debates and that student posts remained topic focused.

The website has a rudimentary ranking system for individual posts and rebuttals. Students were advised that they would not be marked based on the ranking generated using the inbuilt ranking system. However, the system did allow for easy viewing of the number of posts each group had made over the course of the debates.

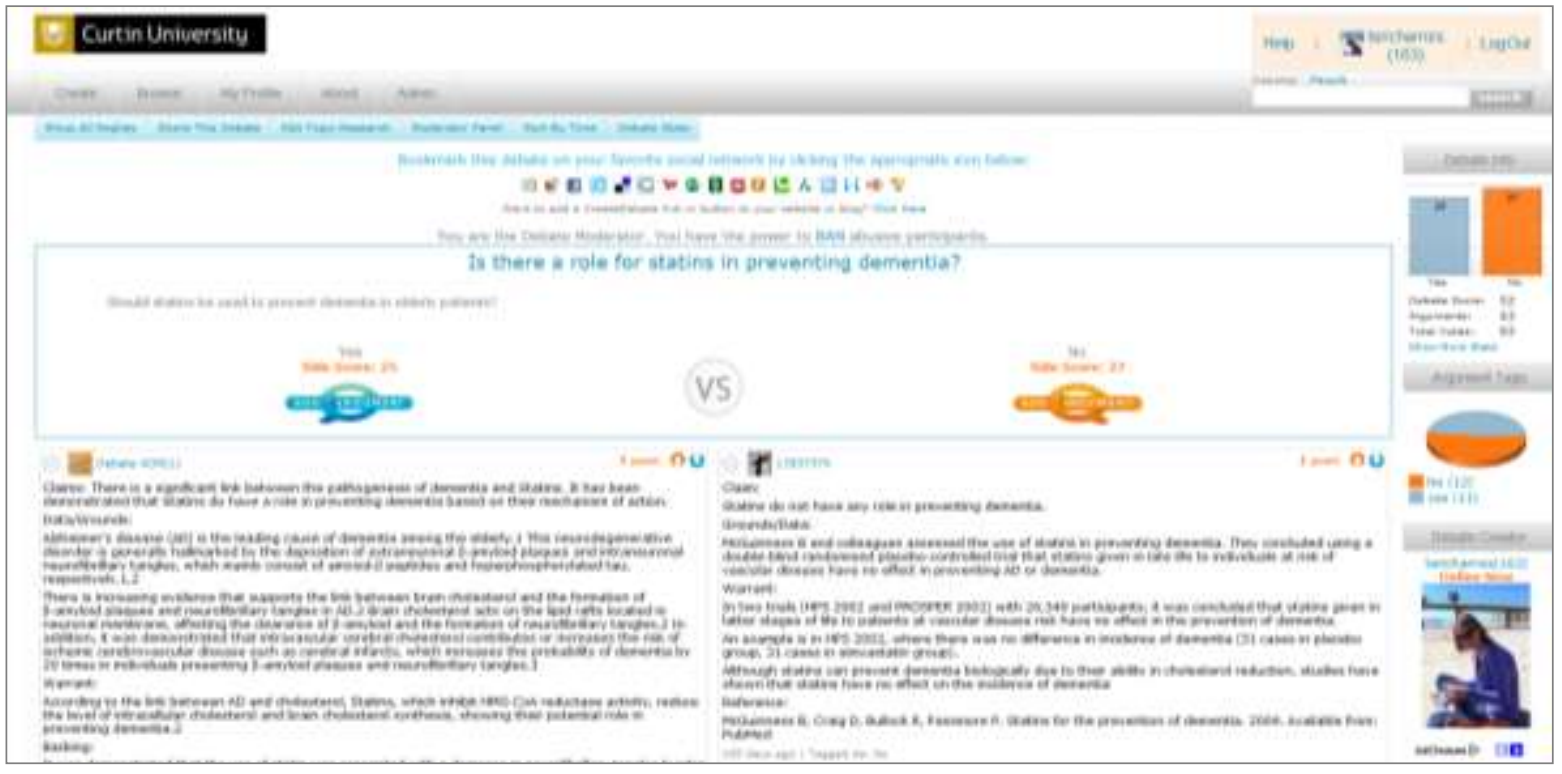

Figure 2: Example debate on www.createdebate.com

\section{Participants:}

All students $(n=136)$ in a final year pharmacotherapy (therapeutics) unit were invited to participate. Ethics approval for the study was granted by the Curtin University Human Research and Ethics Committee. 


\section{Method:}

The study was a pre-test/post-test pre-experimental design (Creswell, 2008) (see Figure 3). Four debate groups were randomly selected for evaluation of level of argumentation and category of informal reasoning (Venville \& Dawson, 2010). Each group was assigned a number and the True Random Number Generator tool (www.random.org) was used to select four groups. A comparison of the debates before and after formative feedback was conducted, assessing both informal reasoning and level of argumentation (see Figure 3, Table 1, Table 2).

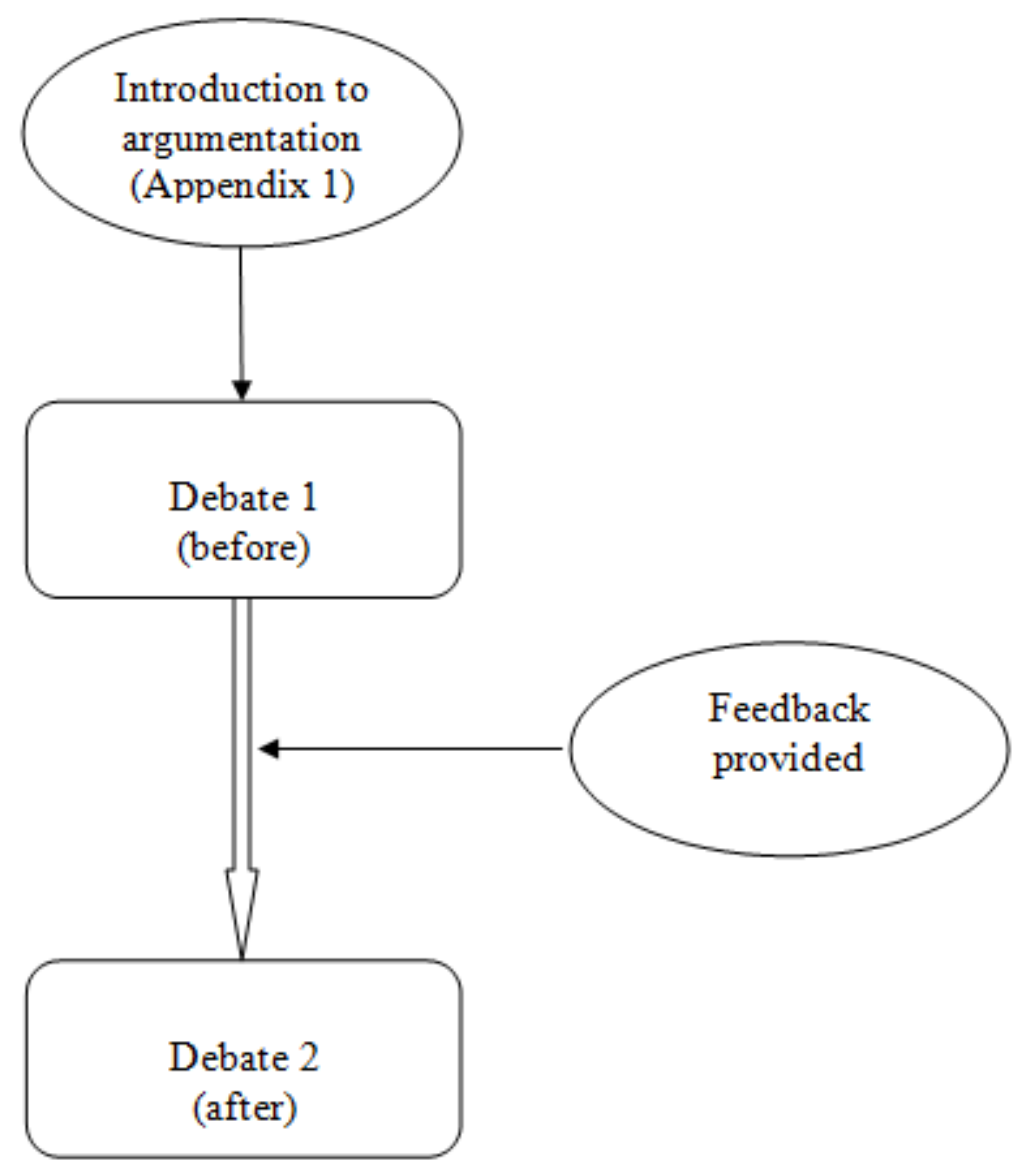

Figure 3: Study design - ovals represent teaching-related actions and rectangles represent learning activities.

In this study informal reasoning is defined as the reasoning students engage in to work out contentious problems without clear-cut solutions. Argumentation is defined as the expression of informal reasoning (Sadler \& Zeidler, 2005). Debate is the term used to describe the overall topic (i.e. Is Cranberry juice effective in reducing the risk of urinary tract infections in the elderly?). Argument is the term used to describe each discrete post submitted by a group to support their side of the debate.

Informal reasoning was assessed by two independent reviewers. The categories described by Sadler and Zeidler (2005) were used to categorise each debate type (see Table 1).

Disagreements were resolved by discussion and consensus. 
Table 1: Categories of Informal Reasoning

\begin{tabular}{|l|l|}
\hline Category & Description \\
\hline Rationalistic & $\begin{array}{l}\text { Logical } \\
\text { Scientific reasoning }\end{array}$ \\
\hline Emotive & $\begin{array}{l}\text { Empathic, sympathetic } \\
\text { Focused on human elements }\end{array}$ \\
\hline Intuitive & $\begin{array}{l}\text { Gut feeling } \\
\text { Immediate Response }\end{array}$ \\
\hline
\end{tabular}

Each group post was also assessed for level of argumentation and the process used for evaluation followed an adapted version of Toulmin's Argumentation Pattern (TAP) (Toulmin, 1958) that was developed by Venville and Dawson (2010) (see Table 2). The posts were assessed independently by two reviewers. Disagreements were resolved by discussion and consensus.

Table 2: Ranking of Arguments

\begin{tabular}{|c|l|}
\hline Level of Argument & Description \\
\hline 1 & $\begin{array}{l}\text { Claim } \\
\text { The conclusion, proposition or assertion }\end{array}$ \\
\hline 2 & $\begin{array}{l}\text { Claim, data (the evidence that supports the claim), and/or warrant (an } \\
\text { explanation of the relationship between claim and data) }\end{array}$ \\
\hline 3 & $\begin{array}{l}\text { Claim, data/warrant, backing (basic assumptions to support the warrant) or } \\
\text { qualifier (conditions under which claim is true) }\end{array}$ \\
\hline 4 & Claim, data/warrant, backing and qualifier \\
\hline
\end{tabular}

Note. Based on Venville \& Dawson's (2010) adapted version of Toulmin's Argumentation Pattern (TAP)

Descriptive statistics were used to analyse the data (i.e. informal reasoning categorisation and argument ranking for debate entries), along with a calculation of kappa with linear weighting to determine level of agreement among reviewers.

\section{Findings}

\section{Results:}

Debates from four randomly selected groups (out of a total of 34 groups) were analysed. As groups were allowed to post as many arguments as they wanted during a set time period (three weeks), each group had a different number of arguments that were analysed over the study period.

When categorising informal reasoning for debate one, reviewers had 100\% agreement. For measure of concordance when assessing level of argument, the calculated kappa was 0.63 . 
In debate one, all four groups posted one argument which was analysable. All arguments were rationalistic and ranked at a Level 3 (100\% of posts).

For debate two, a total of 33 arguments were evaluated on level of argumentation and informal reasoning. The median number of debate posts per group was 7.5 (range 4-14). Again, as with debate one, informal reasoning was categorised as rationalistic in $100 \%$ of debates. Table 3 shows the average level of ranking for arguments by each group.

Table 3: Post-feedback (debate two) ranking of arguments

\begin{tabular}{|c|c|c|}
\hline Debate Group & $\begin{array}{c}\text { Number of } \\
\text { Arguments posted }\end{array}$ & $\begin{array}{c}\text { Median Ranking of } \\
\text { Arguments (range) }\end{array}$ \\
\hline 1 & 8 & $2.5(2-3)$ \\
\hline 2 & 4 & $2.5(2-3)$ \\
\hline 3 & 14 & $2(1-3)$ \\
\hline 4 & 7 & $2(2-3)$ \\
\hline
\end{tabular}

Overall, students were proficient at providing data for each claim they made; $94 \%$ of arguments in debate two were Level 2 or higher. Students provided significant amounts of evidence in each argument; several arguments had five references provided as their evidence.

In terms of Level 3 arguments, in debate one, $75 \%$ of arguments were categorised as level 3 based on having a qualifier. In debate two, 50\% of level 3 arguments had qualifiers and $50 \%$ had backing.

\section{Analysis:}

Students were presented with an entirely different type of assessment, in comparison to previous assessments conducted within their pharmacotherapy units, with this debate assignment. The activity required them to engage in a variety of experiences including group work, online learning, researching, writing, evaluating, analysing and communicating.

Analysis of debate one showed that students required a lot of encouragement to actually engage in the activity. It took until the day before the due date before any arguments were posted, and then, as evidenced in the results, very few arguments were posted at all. Some groups (not analysed) posted no arguments. However, the arguments that were posted were of high quality, as they were all Level 3. None of the posts involved any type 
of rebuttal, given that only one argument per team was posted. Consequently, no interaction between the groups had occurred. Also, none of the arguments posted in debate one followed the argumentation structure provided to them in the orientation (see Appendix 1).

Debate two required less encouragement to get arguments posted, possibly as it was part of the student's formal assessment structure. Students seemed to be focused on posting as many arguments as possible (even though they were told the focus was quality not quantity) and this could be an explanation as to why the level of argument was slightly lower in debate two. The number of arguments posted in debates increased from debate one, and the other major difference was that students engaged in rebuttals. There was actual interaction between groups, including addressing and responding to arguments. In debate two, students were also more consistent with labelling their arguments (claim, data, backing, qualifiers) as recommended during their feedback between debate one and two. However, as arguments were reviewed, it became evident that student's labels were not consistent with reviewer's labels. For example, data provided from research was often labelled as a qualifier or backing by students. This lack of consistency indicates that student may not have fully conceptualised argumentation from the brief introduction provided during unit orientation. Venville and Dawson (2010) found that groups of high school science students who had received specific training in argumentation produced arguments of improved complexity and quality in comparison with groups that did not receive specific training.

In terms of student reflections and comments the main themes were related to workload, applicability and feedback. Students in general felt the workload for this assessment (weighted at 15\% of their final mark for the unit) was too much. They spent a lot of time meeting with their group members and searching for data to support their side of the debate. Interestingly, even though the debate was presented to the students as an opportunity to reduce on campus time, the students still felt the need to meet with their other group members in person; thereby diminishing the flexible learning environment the task was meant to provide.

For applicability of the skills being taught and fostered through this assignment the students had a hard time processing that these skills were applicable in 'real life'. They were provided with an example in the introduction to the unit (Appendix 1) to give the task some context, however students were not able to link this to the applicability of the skills. In the feedback session between debate one and two, how the skills applied to succeeding in the final exam seemed to resonate with some of the students; however, the practical nature of the task still was not apparent to them.

The students also felt that in general, the feedback provided was too generic and not directed enough. The students overwhelmingly wanted specific feedback for their group, rather than the class as a whole. 


\section{Answers to research questions}

1. Assess the impact of teaching strategies on the development of argumentation skills, critical thinking and informal reasoning in pharmacy students.

In conclusion, the introduction provided to students on argumentation, led the students to have a high level of argument (level 3) from the debate one, however feedback provided little additional improvement in their level of argumentation. Their level of informal reasoning (rationalistic) was appropriate to the type of debates given.

2. Assess the impact of teaching strategies on student perceptions to learning argumentation skills, critical thinking and informal reasoning as taught in the context of pharmacotherapy.

Students had a hard time trying to associate the debates with real life scenarios and felt that there was little contextual application to the skills. This will encourage teaching staff to change the style of debate to a more patient/case focused scenario to improve applicability to students. Students were able to develop and apply their rationalistic informal reasoning to debates that would be similar to what is seen in practice.

\section{Conclusion}

\section{What worked well?}

Firstly, the website worked well for the debates. The site was easy to navigate and post on, and students had no complaints or concerns over using it. The site set up is similar to social media sites, therefore the majority of students could relate to the format, and hopefully it made it more engaging for them and encouraged participation.

The two debate system seemed to work as well, in terms of providing the students with some breadth in topics covered. Debate two uptake was quick and students were consistently verbose with their claims, justifications and rebuttals. The amount of posting and quality of arguments is evidence to the fact that the students worked hard at making debate two worthwhile and engaged in lively and timely rebuttals. The second set of debates were engaging and entertaining to read - and hopefully were engaging and entertaining for the students to participate in.

Finally, the introduction of this type of assessment, with the introduction of new skills related to critical thinking and argumentation, worked well with the unit. It offered a new type of assessment to the unit, and gave added dimension to the types of assessments the students engaged in during the unit. Moreover, it helps to further develop the overall pharmacy curriculum to meet specific guidelines as set out by the Australian Pharmacy Council, as well as aligning with the Curtin Graduate Attributes (Curtin Graduate Attributes, 2011). 


\section{What could have been done differently and Implications for implementation?}

In terms of changes for 2012, the focus will be on presenting the debates in a more patient focused way - using patient cases. The students had a hard time trying to understand the practical significance of the skills related to debating; therefore using a more practical setting may help to increase the level of applicability for the students.

Students' level of argument did not increase between debate one and two. As speculated in the results section, this may be due to the number of arguments students posted during debate two. Students were told that the focus of the assessment was on the quality and level of debate, including evidence provided, however, they still seemed quite focused on the need to post more and more arguments. This may be related to the site itself, which ranks debates (winning or losing) based solely on the number of arguments posted under each debate. The students would see this number and ranking every time they logged in, which may have encouraged them to focus on continually posting. This will need to be discussed further with the site administrators to determine if it can be adjusted for our purposes.

The major issue was getting the students to actually engage in debate one. Students had to be told numerous times in class, and via Blackboard, to become involved in debate one. This did not affect the level of argumentation in debate one, however given how few arguments were actually posted, may not be an accurate representation of the students' understanding, at that time point, on argumentation. For 2012, the marking rubric may be modified to allow for some marks to be provided for participation in debate one.

The students also consistently stated that they would like more directed personal feedback between debates one and two, rather than generic feedback provided to the whole class. Teaching staff will discuss different options, but likely written feedback provided to each group will be instituted. Whether or not this feedback can be delivered directly on the website will be further explored.

Finally, it was evident that students require more guidance and information to fully conceptualise argumentation than a brief introduction to the concept at orientation. Therefore supplementary online resources and exemplars will be developed for 2012 .

\section{Implications for future research}

With the modifications proposed to the unit, and improvements in the practical nature of the debates, it will be useful to redo the measurements of informal reasoning and level of argumentation. Although the majority of arguments were Level 3, there were no Level 4 arguments; future research will identify the impact of supplementary resources to improve the complexity and quality of arguments produced.

In addition to this, it would be useful to measure the level of critical thinking itself. In this study, argumentation and informal reasoning were surrogate markers for critical 
thinking. The underlying assumption is that by improving argumentation, that students level of critical thinking was subsequently improved, however this was not measured directly. Future research could employ methods to measure this (McMillan, 1987).

\section{References}

Australian Pharmacy Council. (2009). Accreditation standards version 1.0. Retrieved from http://www.pharmacycouncil.org.au/PDF/Undergraduate $\% 20$ and $\% 20$ Graduate $\% 2$ 0Accreditation $\% 20$ Standards.pdf.

Accreditation Council for Pharmacy Education. (2011). Accreditation standards and guidelines for the professional program in pharmacy leading to the doctor of pharmacy degree. Retrieved from https://www.acpeaccredit.org/pdf/FinalS2007Guidelines2.0.pdf

Creswell, J. (2008). Educational research: Planning, conducting and evaluating quantitative and qualitative research (3rd ed.). Upper Saddle River, NJ: Pearson Prentice Hall.

Curtin Graduate Attributes. (2011). Retrieved from http://otl.curtin.edu.au/teaching learning/attributes.cfm

Erstad, B. L. \& Murphy, J. E. (1994). Developing critical interaction skills in students: Debating clinical pharmacokinetic controversies. American Journal of Pharmaceutical Education, 58, 440-445.

Krathwohl, D. R. (2002). A revision of Bloom's taxonomy: An overview. Theory Into Practice, 41(4), 212-218.

Lieberman, S. A., Trumble, J. M., \& Smith, E. R. (2000). The impact of structured student debates on critical thinking and informatics skills of second year medical students. Academic Medicine, 75(10), S84-S86.

Lin, S. K. \& Crawford, S. Y. (2007). An online debate series for first-year pharmacy students. American Journal of Pharmaceutical Education, 71 (1) 1-8.

McMilllan, J. H. (1987). Enhancing college students' critical thinking: A review of studies. Research in Higher Education, 26, 3-29.

Novak, J. D. (2003). The promise of new ideas and new technology for improving teaching and learning. Cell Biology Education, 2, 122-132.

Poirier, S. (1997). Active involvement of students in the learning process of the American health care system. American Journal of Pharmaceutical Education, 61, 91-97.

Sadler, T. D. \& Zeidler, D. L. (2005). The significance of content knowledge for informal reasoning regarding socioscientific issues: Applying genetics knowledge to genetic engineering issues. Science Education, 89, 71-93.

Saito, A. \& Fujinami, K. (2011). Introduction of formal debate into a postgraduate specialty track education programme in periodontics in Japan. European Journal of Dental Education, 15, 58-62.

Sookaneknun, P., Suttajit, S., Ploylearmsang, C., Kanjanasilp, J., \& Maleewong, U. (2009). Health promotion integrated into a Thai PharmD curriculum to improve pharmacy practice skills. American Journal of Pharmaceutical Education, 73(5), 1-9.

Taylor, K. \& Harding, G. (2007). The pharmacy degree: The student experience of professional training. Pharmacy Education, 7(1), 83-88.

Toulmin, S. (1958). The uses of argument. Cambridge, UK: Cambridge University Press.

Toulmin, S. E. (2003). The uses of arguments (Updated ed.). Cambridge, UK: Cambridge University Press. 
Toulmin, S. E. (1958). The uses of argument. Cambridge, UK: Cambridge University Press.Venville, G. J. \& Dawson, V. M. (2010). The impact of a classroom intervention on grade 10 students' argumentation skills, informal reasoning and conceptual understanding of science. Journal of Research in Science Teaching, 47(8), 952977.

\section{Citation:}

Charrois, T., L. \& Appleton, S. (2012). The Use of Online Debates in Teaching Pharmacotherapy. In A. Herrington, J. Schrape, K. Singh (Eds.), Engaging students with learning technologies (pp. 177-193). Perth, Australia: Curtin University.

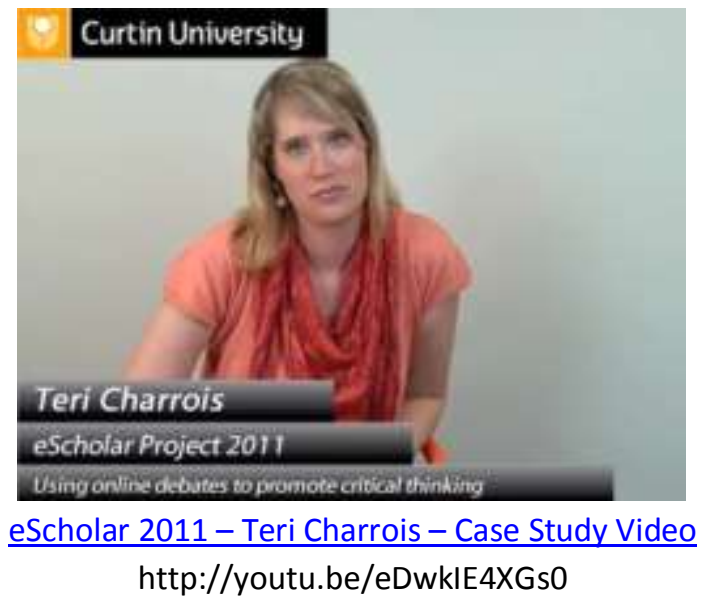




\section{Appendix 1}

\section{Tutorials}

- Have 6, 2 hour face-to-face tutorials

$\circ$ Integrative cases

- Cover new topics and incorporate prior learning

- Other tutorial time (2 hrs/wk) will be for online learning

- Part of the eScholar program

- Integration of blended learning into courses

\section{Why Debate?}

- By discourse and argument, science (pharmacy, medicine) remains objective

- Critique and debate are $\boldsymbol{C} \boldsymbol{O} \boldsymbol{R} \boldsymbol{E}$ to the practice of science (medicine)

\section{Debate}

- Clinical controversy

- No right-or-wrong

- Shades of grey

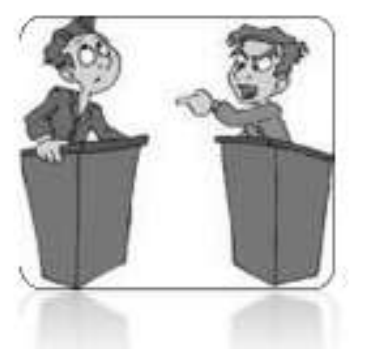

\section{eScholar}

- Aims to support academic staff from across the university to implement new technologies in learning and teaching http://cel.curtin.edu.au/strategic initiatives/ escholars/eScholars2011.cfm

- Online debate to develop critical thinking skills in clinical decision making

\section{Why Debate?}

- Learning is not a process of transmission

○ You sit, I dump information, you memorise

- Learning to argue is important to thinking and understanding/ constructing new ideas

\section{Toulmin's argument diagram}

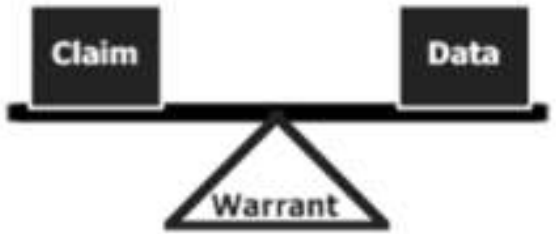




\section{What does an argument look like?}

- Claim

- A statement you want someone to accept

- Grounds/Data

- Data and reasoning behind the claim

- Warrant

o Shows the grounds to be relevant

- Backing

○ Gives additional support to claim

- Qualifier

○ Most, usually, always, sometimes

- Rebuttal

o Pre-empt a counter-argument

\section{You could say}

- Well your doctor prescribed it so you obviously need it.

- That's fine, I'll just cancel that prescription.

- Are you crazy?? Your blood pressure is through the roof!!

\section{Example}

- Claim: You should be on an antihypertensive

- Grounds/Data: your blood pressure is $170 / 90$

- Warrant: high blood pressure can cause CV disease

- Backing: you've had high blood pressure on 3 different occasions

- Qualifier: You are at high risk for CV disease also because of your age and family history

- Rebuttal: Most people don't have too many side-effects on anti-hypertensives

\section{An example...}

- A regular in your pharmacy has not picked up his new prescription for Ramipril 10mg daily. He's an overweight, 68 year old male who smokes. You give him a call to discuss.

He tells you:

"I don't think I need to take this Ramipril every day because I

don't feel sick"

\section{Debating has a role in...}

- Discussing issues with patients

- Discussing issues with other healthcare providers

- Discussing issues with colleagues 


\section{How does it work?}

$\underline{\text { CreateDebate }}$

- For first 6 weeks

- Learn debate-specific terminology

- Upload to Blackboard

○ Split yourselves into groups of $\sim 4$ based on your tutorial groups

- Need 6 groups per tutorial

- Give your 'team' a name email me group members and name

- Poke around on the site

- I'll 'invite' you once everything is ready to go

\section{You will not be marked on}

- Your conclusion to the argument i.e. no right or wrong answer

- If you provide incorrect evidence, that's different

\section{What do I want you to get out of this?}

- To be able to link theory with evidence

\section{- To think}

- Not just relay what it says in the textbook

- To model your answers based on specific patients

\section{How does it work?}

- During Block

- You will be assigned a topic and a side (pro or con) to debate with another team

- You will have 2 debates over the course of the 6-weeks

- First debate

o Practice - no marks

- Feedback on your participation and strengths of arguments provided

- Second debate

o For marks

- Participation, Evidence provided, Strength of argument, and Final report

\section{You will be marked on}

- Participation $(30 \%)$

- Online presence

- Evidence provided (30\%)

- Strength of argument (30\%)

$\circ$ How convincing are you?

- Think about your data, warrant, backing

- Final report $(10 \%)$

- One page

- Reflection of the experience 
